\title{
Type and degree of co-occurrence of the educational communication in a community of inquiry
}

\begin{abstract}
The study analyzes the type and quantity of co-occurrence of social, cognitive, and teaching presence in a Community of Inquiry (CoI). Content analysis of the virtual educational communication shows units of analysis that must be assigned to more than one category. By crossing the categories of the CoI model, we observe that Social Presence is involved in all of the crossings and that graphic, linguistic, and paralinguistic elements change the meaning of the communication in the social, cognitive, and teaching interaction. We demonstrate the communicative richness of the educational encounters in which Social Presence interacts with the other elements and draw conclusions about the importance of support for communication in virtual communication. We stress the need to analyze co-occurrences to achieve a full analysis of computer-mediated communication (CMC).
\end{abstract}

Keywords: Community of inquiry; Computer-mediated communication; Cooccurrence; Virtual classrooms

This is the accepted manuscript published:

Gutiérrez-Santiuste, E. \& Gallego-Arrufat, M.J. (2017). Type and degree of co-occurrence of the educational communication in a community of inquiry. Interactive Learning Environments. https://doi.org/10.1080/10494820.2015.1114498

\section{Introduction}

Qualitative investigation of communication in online educational environments is oriented more to finding and systematizing patterns and considerably less to written communication that does not coincide with a coding schema. Content analysis is 
oriented to the systematic process of coding, classification, and identification of patterns, such as an attempt to identify basic and significant consistencies (Patton, 2002). Coding is, however, a fluid, dynamic process with its own problems (Weber, 1990; Zhang \&Wildemuth, 2009). Mercer (2000) indicates the difficulty of establishing classification systems that reflect the natural variety of communication. It would be useful to solve these classification difficulties. One of the problems with qualitative content analysis is the possibility that a text unit may be assigned to more than one category simultaneously (Lipponen \& Rahikainen, 2003; Strauss \& Corbin, 1998; Strijbos, Martens, Prins, \& Jochems, 2006; Tesch, 1990). This is called co-occurrence, or double categorization. Elasticity of meanings permits models of meaning to emerge. The question of the category to which to assign some units of analysis has often been resolved with intercoder agreement. Even then, some units of analysis-messages (Garrison, Anderson, \& Archer, 2001) or thematic units (Rourke, Anderson, Garrison, \& Archer, 2001) — belong to more than one category. Based on the theory developed by Vygotsky (1978), cognitive processes are social and emerge from and contribute to interactions between the participants (Schrire, 2006). In online communication, this means that each learning dimension must be considered in the context of the other dimensions.

Within the coherent body of existing research on computer-mediated communication (CMC), some studies are oriented to understanding the patterns of human communication and the functions and nature of the text (Garrison, Anderson, \& Archer, 2000). Other studies also indicate a visual analysis methodology that translate data into visible forms that highlight important features, including commonalities and anomalies (Gómez-Aguilar et al, 2010). The Community of Inquiry (CoI) model establishes that virtual communication contains a series of elements that can be 
identified as social, cognitive, or teaching presence. In spite of research findings on the structure, type, and interaction in virtual communication (Naidu \& Järvelä, 2006), we find complex interaction between social and cognitive actions, motivational and emotional issues, and characteristics of the learning context.

The use of emoticons and other linguistic and paralinguistic elements is central to understanding that $\mathrm{CMC}$ employs hybrid characteristics of oral and written language (Halvorsen, 2012). This blend widens the capability of communication to provide textual representations of the characteristics of oral discourse. There are linguistic strategies that compensate for the efficacy of traditional as opposed to online interaction (Hawkes, 2006). Linguistic and paralinguistic signals function as textual representations of the nonverbal characteristics of oral discourse. Studies, some of which use the CoI model, indicate the relationship between the use of emoticons and paralinguistic signs and affective and social aspects of communication. Thus, demonstrations of affect involve tacit recognition of a reciprocal relationship with the community, using the resources of language itself and visual symbols (Garrison \& Anderson, 2003). Such use helps to create social presence in virtual communities. Luor, Wu, Lu, \& Tao (2010) find that positive emoticons highlight considerably the emotion expressed in the discussion and coordination of tasks. Using emoticons can lend support, complement written communication, and facilitate social presence in virtual learning environments (Akayoğlu, Altun, \& Stevens, 2009; Arbaugh et al., 2008; Cobb, 2009; Garrison et al., 2000; Park, 2009), creating a cooperative atmosphere (Smith, 2009) or facilitating expressiveness in the virtual medium. Virtual communication based only on text is a discursive practice oriented less to the form and more to the transmission of meaning (Halvorsen, 2012). 
Our study focuses on descriptive analysis of the complexity of synchronous and asynchronous virtual educational communication in CoIs. This complexity is reflected in the double classification of some units of analysis using the classification system proposed by Garrison et al. (2000) to enable questioning, explanation, and interpretation of the findings. Thus, the goal of this research is to analyze the type and quantity of virtual didactic communications that co-occur in a virtual educational environment.

The goals of the investigation are:

- What types of double classifications appear in the textual virtual educational communication of a CoI?

- How often, and how, do social, cognitive, and teaching presence co-occur with the other presences in a CoI?

- To what extent do linguistic and visual elements change the meaning of social, cognitive, and teaching communication in a CoI?

\section{Qualitative methodology in the CoI model}

The model establishes three interrelated elements in the virtual communication. Cognitive presence refers to the construction of meaning through continuous reflection in a research community (Darabi, Arrastia, Nelson, Cornille, \& Liang, 2011; Garrison, Anderson, \& Archer, 2001). Social presence indicates the capability of the participants to project themselves to each other socially and emotionally to strengthen direct communication, representing themselves clearly as persons (Akyol, Garrison, \& Ozden, 2009; Garrison \& Anderson, 2003). Teaching presence is the act of designing, facilitating, and orienting cognitive and social presences to obtain the expected results (Hosler \& Arend, 2012; Kupczynski, Ice, Wiesenmayer, \& McCluskey, 2010; Morgan, 2011). Some studies add metacognitive presence (Akyol \& Garrison, 2011). 
The CoI model uses qualitative techniques extensively. Rourke \& Anderson (2004) indicate the need to reorient inquiry to inference, even though qualitative research predominates in the analysis of social, cognitive, and teaching presence in various contexts and with diverse objectives (Spector, 2008). Such orientation presents methodological challenges for the researcher, however (Schrire, 2006). One of these is double classification, since the mix of different presences is complex. Analyses to date indicate three types of interrelation between the elements of the CoI:

- Interrelation of the three presences (Stodel, Thompson, \& McDonald, 2006; Garrison, Cleveland-Innes, Koole, \& Kappelman, 2006), often with more than one possible indicator for each classification, without reaching agreement about what classification predominates.

- Interrelation between two presences: Teaching and social presence (De la Varre, Keane, \& Irvin, 2011; Caudle, 2013; Pérez-Mateo \& Guitert, 2012) often seem to mix.

Interrelation between the subclassifications of a presence (Anderson, Rourke, Garrison, \& Archer, 2001). Studies by Kupczynski et al. (2010) and Weerasinghe, Ramberg, \&Hewagamage (2012) find a high percentage of double classifications in teaching presence.

\section{Method}

\section{Contextualization}

In this study, the methodology used in the virtual sessions (with chats, forums, and emails) corresponds to a socio-constructivist perspective in which professors adopt the role of manager, guide, and tutor. The students are to analyze educational content —in videos, ebooks, blogs, forums, wikis, webpages_-prior to chat sessions of 40 minutes 
each, which are used as a place to share, discuss, and relate socially. The forums were open for communication over a three-month period and were later used as a place for reflection, agreement, and summary of the ideas worked on together. The chat and forum activities form part of the course Information and Communication Technology in Education at a Spanish university. Email was used to complement individual questions (concerning organization).

\section{Sample}

The sample was composed of 98 students from the second year of a Bachelor's degree program in Education and two professors. The students were 19-38 years of age $(\bar{x}=22.74 ; \quad=3.67 ;$ mode $=21)$. The gender distribution was $88.35 \%$ women and $11.65 \%$ men. Incidental sampling was used.

\section{Procedure}

We performed a content analysis (Berelson, 1952) of the online communications, using the following sequence (Naidu \& Järvelä, 2006):

(1) Determination of the unit of analysis: We chose the thematic unit (Rourke, Anderson, Garrison, \& Archer, 2000; Strijbos et al., 2006), understood as unit of meaning, expression of an idea.

(2) Development of segmentation procedure: The synchronous communications consisted of 63 chats and the asynchronous communications of two forums and 302 emails. An indicator was assigned to each thematic unit. We then crossed the different subclassifications in N.Vivo v.8 (which groups various indicators) to confirm which crossings were observed and to what extent. We quantified the communications for better comprehension of the results through simple counting techniques and calculated the frequencies and percentages. 
(3) Determination of the reliability of the segmentation procedure: Next, we analyzed agreement in the classification system, ensuring that the classifications were defined correctly according to an intercoding analysis (ICC $=.584$ is moderate and acceptable, Landis \& Koch, 1977).

(4) Development of coding classifications and rules: These were established following the proposal by Garrison \& Anderson (2003), adapted in other studies (Akayoğlu et al., 2009; Garrison, Cleveland-Innes, \& Fung, 2004; Garrison et al., 2006; Park, 2009) and modified by findings in the process of coding the data themselves (Lampert \& Ervin-Tripp, 2014). We created three similar classification systems (for the chats, forums, and e-mails). Each classification system included three classifications (Social P., Cognitive P., and Teaching P.), composed of a series of subclassifications, which were in turn composed of a series of indicators. During the coding process, we created the new classification "Support for communication" independently and the subclassification "Social Other" (for thematic units not included in any of the existing classifications).

(5) Determination of the reliability of the coding categories: To establish the degree of reliability in assigning thematic units to indicators, we performed a double review of the classification and a cross-matrix of all indicators (Denzin\& Lincoln, 2011).

\section{Results}

We classified a total of 13,420 thematic units. The chats contained $15.02 \%$ double classifications (1,537 thematic units), the forums $8.56 \%$ (164 thematic units), and the emails $2.7 \%$ (28 thematic units) (Table 1).

Table 1 over here. 
Social Presence contains the subclassifications: Affect, with indicators of emotion, open expression, gratitude, and appreciation; Open Communication, with responses to questions not related to the content, acceptance of corrections or explanations, and use of vocatives; Cohesion, with use of inclusive pronouns and greetings; and Social Other, with thematic units of social character that did not coincide with any of the previous operative definitions.

Cognitive Presence is organized into the subclassifications: Exploration, with indicators of divergence from a previous message, exchange of information, suggestions/ comments/advice on learning topics, identification of relevant new information and requests for clarification or expansion of concepts; Integration, with indicators of agreement with a previous message, synthesis of information, contribution of solutions, confirmation of understanding of concepts; and Resolution, with indicators of application or use of previous messages, confirmation, defense of a position, and sentences that request or respond to the material worked on in the sessions.

Teaching Presence contained the subclassifications: Design and Organization, with general organizational questions, establishment of a schedule, and clarification of how to use the technology tools; Facilitation of Discussion, with encouragement, praise, or reinforcement of classmates' contributions; and Direct Teaching, with summary of discussion content and provision of knowledge from different sources.

Support for Communication included thematic units with some element that strengthened and/or modified the meaning of the communication, such as exclamation marks, paralinguistic emphasis, repetition of content, and use of emoticons, interjections, capital letters, etc.

The double classifications found in the virtual communications fell into two main groups: 
- Between social, cognitive, and teaching presence (chat: $78.19 \%$, forums:

$73.17 \%$, and emails: $35.71 \%)$.

- Between support for communication and the presences (chat: $21.8 \%$, forums: $26.83 \%$, and emails: $64.28 \%)$.

\section{Co-occurrences among the Presences}

The double classifications or co-occurrences between the elements of the CoI model involve Social Presence as a whole. We analyze them with themselves (Table 2), with Cognitive Presence (Table 3), and with Teaching Presence (Table 4). The percentages in all of the research figures are obtained over the number of co-occurrences in each tool independently.

With itself (Social Presence / Social Presence)

According to the tools, $12.75 \%$ of the co-occurrences appear in the chats, $13.32 \%$ in the forums, and $5.25 \%$ in the emails (Table 2).

Table 2 over here.

Table 2 presents the incidence of double classification in the communications. The findings demonstrate the connection between affect and group cohesion. The students use written language, combining affective statements with the idea of a link to the learning community and inclusion of the members of the group. The highest percentage refers to the co-occurrence of expressions of affect-such as emotions, one's own personality, and gratitude — and open expression, classified together with vocatives, inclusion, and greetings. An example of double classification between Cohesion and Affect is: "Thanks for having accepted me in this MOD time." Double classification also occurs to a lesser extent between Cohesion and Open Communication. We can conclude that the communication has fostered a group dynamic and high degrees of cordial interaction. 


\section{Cognitive Presence / Social Presence}

According to the tools, $69.36 \%$ of the double classifications occur in the chats and 47.01\% in the forums. There are no double classifications in the emails (Table 3).

Table 3 here.

Double classification is often related to Integration / Cohesion in the case of the chats and forums. Thus, agreement corresponds to the use of vocatives and inclusive pronouns. An example in a chat is: "I agree with you, Blanco, about the collaborative character of the knowledge generated in this kind of communication and the more relaxed psychological atmosphere, maybe, than in a face-to-face situation." The analysis shows double classifications of Exploration and Cohesion in exchange of information or presentation of personal ideas with the use of vocatives or sentences with inclusive pronouns. For example: “Rubí, what elements are you referring to? I haven't seen them"; "I think we are not 100\% prepared for this kind of thing and should prepare much more if we want to be on the same level as the other students." Resolution / Cohesion appears to a lesser extent when the opinion on tools, activities, and exercises performed virtually co-occurs with vocatives and the use of inclusive pronouns.

\section{Teaching Presence / Social Presence}

Double classifications in Social and Teaching Presence are found in different percentages by tool: in the chats $(17.9 \%)$, in the forums $(9.99 \%)$, and in the emails $(25 \%)($ Table 4$)$.

Table 4 over here.

Double classifications were found between sentences related to teaching and to organizational questions and those providing guidelines for development; sentences that clarify, guide, or orient people to use of the technology tool; and sentences that explain or correct social behavior in the virtual communications, with cohesive aspects of the 
group. For example: "What is important is the Excel table that MOD3 and I have; there you can find all the notes from all the projects students have done."

Contributions related to issues of facilitating discussion also stand out (encouraging contributions from participants by strengthening the contributions and encouraging those who are passive, drawing out the opinions of the participants to promote debate on study topics, and responding to or clarifying technical concerns), again with group cohesion.

\section{Double classifications between Support for communication and Presences}

The classification Support for Communication (324 thematic units) emerged inductively during the classification process. The virtual communications contained elements of Social Presence, which also co-occurs with Cognitive and Teaching Presence. Support for Communication represent $21.8 \%$ of the co-occurrences in the chats, $26.84 \%$ in the forums, and $64.28 \%$ in the emails. The graphic, linguistic, and paralinguistic elements that serve as Support for Communication correspond to the use of single or multiple question marks (“In the schools..., but at home ¿?????”), single or multiple exclamation marks, (“And it's not enough that it's written as a norm in a document!!!!!!”), repetition of letters or syllables (“It's that people don't have the foggiest idea until it takes form that they are going to spend a loooot of time"), repeating words ("thank you, thank you") or emoticons. Table 5 represents the percentages over the total of Support for Communication.

Support for Communication with Social Presence

The relationships established are $14.96 \%$ (chats), $10.37 \%$ (forum), and $57.14 \%$ (emails) (Table 5).

Table 5 here.

The greatest proportion of co-occurrence appears with various aspects of cohesion. For example, with greetings (here, a closing), "until next week =)"; gratitude 
“thanks a lot!!!!”; and vocatives, “it’s true, Rubí, that section is really good!!!” It also occurs with Affect (emotions): "Wow, the time has gone so fast!" The elements modifying and/or strengthening the meaning of the communication are especially closely related to demonstrating appreciation or expressing agreement with classmates. They also include Social Other. For example, "Excuse my confusion before-I had had bad experiences with the contacts who added me, ha ha." In the case of Open Communication, we find co-occurrences with the three communication tools; strengthening elements are used along with greetings and vocatives. Co-occurrences with affective communication occur especially with gratitude and expression of satisfaction.

\section{Support for Communication and Cognitive Presence}

We find a lower percentage of these co-occurrences (Table 6), and they occur only in the chats $(27.44 \%)$ and the forums $(43.17 \%)$.

Table 6 over here.

We find the highest percentages with Integration (especially in thematic units on agreement with a message), Exploration (exchange of information, for example, “...in addition to grammar, it includes vocabulary, dialogues... games!"), and also Resolution (confirmation of and opinion about tools, activities, and exercises done).

\section{Support for Communication and Teaching Presence}

The lowest percentages of co-occurrence of the linguistic and graphic support are found

with Teaching Presence (chat: 3.95\%, forum: 18.18\%, and emails: 11.11\%) (Table 7).

Table 7 over here.

In the case of encouraging or reinforcing classmates' contributions, for example, we find: “... it's great that you find problems... Opalino.” On organizational issues, we also find thematic units oriented to the use of the technology tool. For example: “... 
time is running out. We can keep debating and contributing information to share in the forum. I encourage you to participate in it!”

\section{Conclusions}

This study analyzes the kind and degree of co-occurrences or double classifications in a CoI, observing that virtual educational communication is a dynamic, fluid process. Communicative richness is expressed by crossing social, cognitive, and teaching issues, supported, highlighted, and/or modified by linguistic, paralinguistic, and graphic elements, which give the textual communication nuances not obtained with visual elements.

This investigation helps to resolve the difficulty of establishing classification systems that correspond to the natural variety of communication (Mercer, 2000). By crossing classification systems, we can obtain information on the type and degree of cooccurrences in the virtual didactic communication. The richness and complexity of communicative interaction in virtual educational environments cannot be analyzed only by assigning units of analysis to a type of category but must also include the interaction between these categories. In the future, virtual communication can be analyzed under the proposed "pedagogical patterns" used by Seoane-Pardo \& García-Peñalvo (2014). This proposal can provide valuable information to understand educational communication in virtual environments.

Communicative richness is especially apparent in the chats, due possibly to their resemblance to oral communication, showing the hybrid character of this kind of communication (Halvorsen, 2012), with great variety in the interrelations between the indicators analyzed.

This study confirms the elasticity and flexibility of communication in virtual educational environments. We can establish a model of meaning concerned especially 
with Social Presence, observing that all thematic units analyzed in the case of the presences in the CoI model interrelate with this presence. We see that cognitive processes are social, producing inter-encouragement and complex interaction of social and cognitive actions (Schrire, 2006; Naidu \& Järvelä, 2006).

The substantial percentage of social interrelations in all of the tools (chats, forums, and emails) with the other presences shows that virtual communication reflects the personal projection of each member of the CoI, who projects his or her self as a real person and reveals his or her personality (Akyol, Garrison \& Ozden, 2009). Social aspects co-occur with the cognitive and teaching aspects inherent in the virtual educational context (Pérez-Mateo \& Guitert, 2012). Discursive development within the community through the complementarity of social, cognitive, and teaching aspects shows the richness of communicative nuances generated by the people who interact.

The findings demonstrate the complexity of social communication, especially its intertwining of aspects of group cohesion (for example, the use of vocatives, inclusive pronouns, and greetings) with affective aspects, such as expression of emotions or gratitude or demonstrations of appreciation. The cohesive aspects of the group also cooccur when there is agreement with the interventions of other members of the group. Cognitive aspects are doubly classified with Social Presence, especially when the thematic units allude to integration (agreement with the messages of other members of the group) with cohesion (use of vocatives), and the presentation of solutions or synthesis of previous ideas with the use of inclusive pronouns such as "we" or "our group" as members of a $\mathrm{CoI}$ or future Education professionals.

Teaching aspects are also interrelated with social aspects, especially with group cohesion (use of vocatives and inclusive pronouns) when orienting people to the use of technology tools or general organizational questions. Our study confirms the findings of 
De la Varre et al. (2011) and Caudle (2013) on the relationships between social and teaching presence.

In contrast, we do not find interrelations between the three presences (Stodel et al., 2006), nor do we find double classification between teaching and cognitive presence (Anderson, Rourke, Garrison \& Archer, 2001; Kupczynski et al., 2010).

We also observe that a high percentage of the paralinguistic, linguistic, and graphic text-based elements are related to Social Presence. The students and professors modify — expand or reinforce — the cognitive and teaching elements using paralinguistic tools available on the computer keyboard through linguistic strategies (Hawkes, 2006) and graphic strategies (Garrison \& Anderson, 2003).

Support for Communication was used especially in emails related to Social Presence, which shows that direct and open communication of the professors with students is fluid between people feel marked cohesive charisma.

The relation between Support for Communication and Cognitive Presence was observed in aspects of integration (presentation of solutions or explanations or synthesis of the information constructed, based on other ideas), but we also found aspects related to exploration or decision making. Further, support for communication is interrelated with Teaching Presence, especially when someone encourages, praises, or recognizes the contributions of the other members of the group.

The data obtained support the importance of social relations in virtual learning communities, considering the interrelation between the elements of the CoI model through rich discursive development full of communicative nuances.

\section{References}


Akayoğlu, S., Altun, A., \&Stevens, V. (2009). Social presence in synchronous textbased computer-mediated communication.Eurasian Journal of Educational Research, 34, 1-16.

Akyol, Z., \& Garrison, D. R. (2011). Assessing metacognition in an online community of inquiry. Internet and Higher Education, 14, 183-190. doi:10.1016 /j.iheduc.2011.01.005

Akyol, Z., Garrison, R., \&Ozden, M. Y. (2009). Online and blended communities of inquiry: Exploring the developmental and perceptional differences. International Review of Research in Open \& Distance Learning, 10(6), 65-83.

Anderson, T., Rourke, L., Garrison, D. R., \& Archer, W. (2001). Assessing teaching presence in a computer conferencing context. Journal of Asynchronous Learning Networks, 5 (2).

Arbaugh, J. B., Cleveland-Innes, M., Diaz, S. R., Garrison, R., Ice, P., Richardson, J. C., \& Swan, K. P. (2008). Developing a community of inquiry instrument: Testing a measure of the community of inquiry framework using a multi-institutional sample. Internet and Higher Education, 11(3-4), 133-136. doi:10.1016/ j.iheduc.2008.06.003

Berelson, B. (1952). Content analysis in communication research. Glencoe, ILL: Free Press.

Caudle, L. A. (2013). Using a sociocultural perspective to establish teaching and social presence within a hybrid community of mentor teachers. Adult Learning, 24(3), 112-120. doi:10.1177/1045159513489112

Cobb, S. C. (2009). Social presence and online learning: A current view from a research perspective. Journal of Interactive Online Learning, 8(3), 241-254.

Darabi, A., Arrastia, M. C., Nelson, D. W., Cornille, T., \& Liang, X. (2011). Cognitive presence in asynchronous online learning: A comparison of four discussion strategies. Journal of Computer Assisted Learning, 27(3), 216-227. doi:10.1111/j.1365-2729.2010.00392.x

De la Varre, C., Keane, J., \& Irvin, M. J. (2011). Dual perspectives on the contribution of on-site facilitators to teaching presence in a blended learning environment.The Journal of Distance Education, 25(3).

Denzin, N. K., \& Lincoln, Y. S. (Eds.). (2011). The Sage handbook of qualitative research $\left(4^{\text {th }}\right.$ ed.). Thousand Oaks, CA: Sage. 
Garrison, D. R., \& Anderson, T. (2003). E-learning in the 21st century: A framework of research and practice. London: RoutledgeFalmer.

Garrison, D. R., Anderson, T., \& Archer, W. (2001). Critical thinking and computer conferencing: A model and tool to assess cognitive presence. American Journal of Distance Education, 15(1), 1-18.

Garrison, D. R., Cleveland-Innes, M., \& Fung, T. (2004). Students' role adjustment in online communities of inquiry: Model and instrument validation. Journal of Asynchronous Learning Networks, 8(2), 61-74.

Garrison, D. R., Cleveland-Innes, M., Koole, M., \&Kappelman, J. (2006). Revisiting methodological issues in transcript analysis: Negotiated coding and reliability. The Internet and Higher Education, 9, 1-8. doi:10.1016/j.iheduc.2005.11.001

Garrison, R., Anderson, T., \& Archer, W. (2000). Critical inquiry in a text-based environment: Computer conferencing in higher education. Internet and Higher Education, 11(2), 1-14. doi:10.1016/S1096-7516(00)00016-6

Gómez-Aguilar, D. A., Suárez-Guerrero, C., Therón-Sánchez, R., García-Peñalvo, F. J. (2010).Visual analytics to support e-learning. In M. B. Rosson (Ed.), Advances in Learning Processes (pp. 207-228). Croatia: In-Thech. doi: 10.5772/7932

Halvorsen, A. (2012). Patterns of emoticon usage in ESL students' discussion forum writing.CALICO Journal, 29(4), 694-717.

Hawkes, M. (2006). Linguistic discourse variables as indicators of reflective online interaction.The American Journal of Distance Education, 20(4), 231-244.

Hosler, K. A., \&Arend, B. D. (2012). The importance of course design, feedback, and facilitation: Student perceptions of the relationship between teaching presence and cognitive presence. Educational Media International, 49(3), 217-229. doi:10.1080/09523987.2012.738014

Kupczynski, L., Ice, P., Wiesenmayer, R., \&McCluskey, F. (2010). Student perceptions of the relationship between indicators of teaching presence and success in online courses.Journal of Interactive Online Learning, 9(1), 23-43.

Lampert, M. D., \& Ervin-Tripp, S. M. (2014). Structured coding for the study of language and social interaction. In J. A. Edwards \& M. D. Lampert (Eds.), Talking data. Transcription and coding in discourse research $\left(3^{\text {rd }} \mathrm{ed}\right.$.). New York: Lawrence Erlbaum.

Landis, J. R., \& Koch, G. G. (1977). The measurement of observer agreement for categorical data.Biometrics, 33, 159-174. 
Lipponen, L., \&Rahikainen, M. (2003). Patterns of participation and discourse in elementary students' computer-supported collaborative learning.Learning and Instruction, 13, 487-509. doi:10.1016/S0959-4752(02)00042-7

Luor, T., Wu, L., Lu, H.-P., \&Tao, Y.-H. (2010). The effect of emoticons in simple and complex task-oriented communication: An empirical study of instant messaging. Computers in Human Behavior, 26, 889-895.doi:10.1016/j.chb.2010.02.003

Mercer, N. (2000).Words \& Minds. London: Routledge.

Morgan, T. (2011). Online classroom or community-in-the-making?Instructor conceptualizations and teaching presence in international online contexts.The Journal of Distance Education, 25(1), 1-14.

Naidu, S., \&Järvelä, S. (2006). Analyzing CMC content for what? Computer \& Education, 46, 96-103. doi:10.1016/j.compedu.2005.04.001

Park, C. L. (2009). Replicating the use of a cognitive presence measurement tool. Journal of Interactive Online Learning, 8(2), 140-155.

Patton, M. Q. (2002).Qualitative research and evaluation methods. Thousand Oaks, CA: Sage.

Pérez-Mateo, M., \&Guitert, M. (2012). Which social elements are visible in virtual groups? Addressing the categorization of social expressions. Computer \& Education, 58, 1234-1246. doi:10.1016/j.compedu.2011.12.014

Rourke, L., \& Anderson, T. (2004). Validity in quantitative content analysis.Education Technology Research and Development, 52(1), 5-18.

Rourke, L., Anderson, T., Garrison, R., \& Archer, W. (2000). Methodological issues in the content analysis of computer conference transcripts.International Journal of Artificial Intelligence in Education, 11, 8-22.

Rourke, L., Anderson, T., Garrison, D. R., \& Archer, W. (2001). Assessing social presence in asynchronous text-based computer conferencing. The Journal of Distance Education, 14(2), 50-71.

Schrire, S. (2006). Knowledge building in asynchronous discussion groups: Going beyond quantitative analysis. Computers \& Education, 46, 49-70. doi:10.1016/j.compedu.2005.04.006

Seoane-Pardo, A.M., \& García-Peñalvo, F. J. (2014). Pedagogical patterns and online teaching. In F. J. García-Peñalvo \& A.M. Seoane (Eds.), Online tutor 2.0: Methodologies and case studies for successful learning (pp. 298-316). Hershey, PA: IGI Global. 
Smith, E. S. (2009). Writing web-based distance education courses for adult learners. American Journal of Distance Education, 15(2), 53-65. doi:10.1080/08923640109527084.

Spector, J. M. (2008). Research on educational communications and technology. (J. M. Spector, M. D. Merrill, J. Van Merriënboer, \& M. P. Driscoll, Eds.) (3 ${ }^{\text {rd }}$ ed.). New York: Lawrence Erlbaum.

Stodel, E. J., Thompson, T. L., \& McDonald, C. J. (2006). Learners' perspectives on what is missing from online learning interpretations through the Community of Inquiry framework. International Review of Research in Open and Distance Learning, 7(3), 1-24.

Strauss, A., \& Corbin, J. (1998). Basics of qualitative research: Techniques and procedures for developing Grounded Theory (2nd ed.). London, UK: Sage Publications, Inc.

Strijbos, J.-W., Martens, R. L., Prins, F., \&Jochems, W. M. G. (2006). Content analysis: What are they talking about? Computers \& Education, 46, 29-48. doi:10.1016/j.compedu.2005.04.002

Tesch, R. (1990). The mechanics of structural qualitative analysis.In Qualitative research.Analysis types \& software tools (pp. 103-112). Bedford, UK: Routledge.

Vygotsky, L. (1978). Mind in society. Cambridge, MA: Harvard University Press.

Weber, R. P. (1990). Content analysis. In Basic Content Analysis ( $2^{\text {nd }}$ ed., pp. 117-124). Thousand Oaks, CA: Sage.

Weerasinghe, T. A., Ramberg, R., \&Hewagamage, K. P. (2012). Inquiry-based learning with or without facilitator interactions.The Journal of Distance Education, 26(2).

Zhang, Y., \&Wildemuth, B. M. (2009). Qualitative analysis of content. In B. M. Wildemuth (Ed.), Applications of Social Research Methods to Questions in Information and Library Science (pp. 308-319). Westport, CT: Libraries Unlimited. 
Table 1. Combinations of double classifications by tool

$\begin{array}{llll} & \text { Chats } & \text { Forums } & \text { Emails } \\ \text { Social P. / Social P. } & 10.44 \% & 9.76 \% & 17.86 \% \\ \text { Social P. / Cognitive P. } & 53.86 \% & 56.10 \% & - \\ \text { Social P./ Teaching P. } & 13.90 \% & 7.32 \% & 17.86 \% \\ \text { Social P. / Support } & 14.96 \% & 10.37 \% & 57.14 \% \\ \text { Cognitive P. / Support } & 5.98 \% & 11.59 \% & - \\ \text { Teaching P. / Support } & .86 \% & 4.88 \% & 7.14 \%\end{array}$


Table 2. Distribution by tool of the double classifications of Social Presence with itself

Affect / Cohesion

Affect / Open Communication

Cohesion / Open Communication

Affect / Social Other

Cohesion / Cohesion
Chats Forums Emails

$7.02 \% \quad 4.16 \% \quad 5.25 \%$

$.94 \%$

$4.62 \% \quad 1.66 \% \quad-$

$.17 \%$

$7.50 \%$ 
Table 3. Distribution by tool of the double classifications of Cognitive Presence with Social Presence

Triggering Event / Cohesion

Chats

Forums

Exploration / Affect

$1.20 \%$

Exploration / Cohesion

$.17 \%$

$15.07 \%$

$7.50 \%$

Integration / Affect

$.09 \%$

Integration / Open Communication

$.09 \%$

Integration / Cohesion

$43.15 \%$

$35.71 \%$

Resolution / Affect

$1.71 \%$

Resolution / Cohesion

$7.88 \%$

$3.80 \%$ 
Table 4. Distribution by tool of the double classifications of Teaching Presence with Social Presence

$\begin{array}{lrll} & \text { Chats } & \text { Forums } & \text { Emails } \\ \text { Organization / Affect } & 2.83 \% & - & - \\ \text { Organization / Open Communication } & .51 \% & - & - \\ \text { Organization / Cohesion } & 7.71 \% & 3.33 \% & 15.00 \% \\ \text { Facilitating Discussion / Affect } & .17 \% & - & - \\ \text { Facilitating Discussion / Cohesion } & 3.77 \% & 1.66 \% \% & 10.00 \% \\ \text { Direct Instruction / Cohesion } & 2.65 \% & & - \\ \text { Direct Instruction / Open } & .26 \% & - & - \\ \text { Communication } & & & \end{array}$


Table 5. Percentage of double classifications between Support for Communication and Social Presence

$\begin{array}{lllc} & \text { Chats } & \text { Forums } & \text { Emails } \\ \text { Affect } & - & 11.36 \% & 5.55 \% \\ \text { Open Communication } & 14.02 \% & 6.81 \% & \square \square \square \square \square \square \\ \text { Cohesion } & 37.19 \% & - & 44.44 \% \\ \text { Social Other } & 1.21 \% & 20.45 \% & 22.22 \%\end{array}$


Table 6. Distribution by tool of double classifications of Cognitive Presence and Support for Communication

Chats Forums

Triggering Event

$3.96 \%$

Exploration

$7.02 \%$

$9.09 \%$

Integration

$10.67 \%$

$27.27 \%$

Resolution

$5.79 \%$

$6.81 \%$ 
Table 7. Percentage of double classification between Support for

Communication and Teaching Presence

Organization

Facilitating Discussion

Direct Instruction
Chats Forums Emails

$2.13 \% \quad 4.54 \%$

$1.82 \% \quad 6.81 \%$

$6.83 \%$ 